Buletin Psikologi

2016, Vol. 24, No. 1, 22 - 31

DOI: $10.22146 /$ bpsi.16358
ISSN 0854-7106 (Print)

ISSN 2528-5858 (Online)

https://jurnal.ugm.ac.id/buletinpsikologi

\title{
Epilepsi dan Budaya
}

\author{
Nurwinta Catur Wulan Maryanti
}

Fakultas Psikologi Universitas Gadjah Mada

\begin{abstract}
This paper shows an analysis on several literature reviews. The aim of this article is to understand epilepsy in multiple cultures. Epilepsy is considered different across countries and cultures. It is a neurological disorder, characterized by spontaneous and periodic seizures. It is not a new illness. In ancient times, epilepsy has been known as a form of religious experience associated with satanic or sacred diseases, spirits' attacks, 'possessions,' and in some cultures identical to madness. Epilepsy has detrimental effects on patient psychologically, economically, socially and culturally. These effects include social isolation, stigmatization, or disability that can lead to poor learning outcomes and job opportunities. Negative social stigma, negative attitudes, misunderstandings, discrimination, and misperceptions experienced by epileptic patients around the world, causes them to feel trapped in the dark and socially withdrawn.
\end{abstract}

Keywords: culture, epilepsy, stigma

\section{Pengantar}

Ilustrasi Kasus 1. Kasus ini terjadi di Indonesia, tepatnya di Bandung (Fokusjabar.com). Seorang pria berusia 24 tahun, tergeletak di teras Bank Bukopin Antapani Bandung, setelah terjatuh dan langsung pingsan. Pria tersebut terjatuh saat akan meloncati parit dari trotoar jalan menuju pelataran parkir. Teman korban menuturkan, dirinya bersama korban sedang berjalan di trotoar tiba-tiba saja korban malah meloncati parit tersebut. Sebelumnya sempat diduga tewas. Namun ternyata tidak, dari informasi yang diperoleh, korban diduga menderita penyakit epilepsi. Hal itu dibenarkan setelah teman korban menghubungi keluarga korban. "Dia (korban) memang suka begitu nanti juga sadar sendiri," ucap teman korban saat menghubungi keluarga korban.

\footnotetext{
${ }^{1}$ Korespondensi mengenai artikel ini dapat dilakukan melalui: wintacwm@gmail.com
}

Ilustrasi Kasus 2. Pasien An. R, usia 13 tahun, pendidikan kelas 1 SMP. Datang ke poli saraf Rumah Sakit Cipto Mangunkusumo (RSCM) dengan keluhan utama riwayat kejang 'kelojotan' berulang sejak tiga bulan sebelum datang ke RSCM. Kirakira 1 kali/bulan dengan pola serupa. Serangan biasanya terjadi saat pasien sedang duduk menonton televisi. Sejak dua tahun sebelumnya (kelas VI SD) keluarga dan guru memperhatikan bahwa pasien sering "bengong". Terkadang pasien harus dikejutkan agar terbangun. Apabila tidak dibangunkan maka lama waktu "bengongnya" bisa mencapai lima menit. Frekuensi 10-20 kali/hari. Setelah terbangun pasien tidak ingat apa-apa mengenai kejadian saat pasien "bengong".

Dari penuturan ibu pasien didapatkan beberapa cerita saat serangan "bengong" terjadi, antara lain saat menunggu mobil angkutan umum bersama teman-teman, ketika mobil datang teman yang lain naik ke mobil sedangkan pasien hanya diam saja 
sehingga tertinggal. Saat di angkutan umum pasien juga sering tidak sadar, tiba-tiba sudah terlewat beberapa ratus meter dari tempat biasa turun. Guru di sekolah mengatakan bahwa pasien lambat saat mengerjakan tugas karena sering melamun. Namun sejauh ini nilai prestasi sekolah relatif baik. Saat sedang diajak bicara oleh ibunya, sering tiba-tiba "bengong", dan baru terbangun/sadar setelah dikejutkan.

\section{Pengertian Epilepsi}

Gangguan epilepsi dapat menyerang pada siapa pun di seluruh dunia, anak-anak, orang dewasa, para orang tua bahkan bayi yang baru lahir. Rentang usia orang dengan epilepsi adalah 20-70 tahun per 100.000 orang, dengan prevalensi jumlah 4-10 orang per 1000 (Baker \& Jacoby, 2002). WHO (2009) menambahkan bahwa sekitar 50 juta penduduk di seluruh dunia menderita epilepsi. Sebanyak $90 \%$ orang dengan epilepsi ditemukan pada negara-negara berkembang, dan sebagian besar belum mendapatkan perlakuan sesuai yang mereka butuhkan.

Epilepsi berasal dari bahasa Yunani "epilepsia" yang artinya adalah gangguan neurologis umum kronis yang ditandai dengan kejang berulang tanpa alasan, kejang sementara dan/atau gejala dari aktivitas neuronal yang abnormal, berlebihan atau sinkron di otak. Epilepsi oleh Hipocrates diidentifikasi sebagai sebuah masalah yang ada kaitannya dengan otak. Epilepsi terkait dengan kinerja sistem saraf pusat di otak kita. Saraf di otak berfungsi sebagai koordinator dari semua pergerakan seperti, penglihatan, peraba, bergerak, dan berpikir. Pada penderita epilepsi, sistem saraf pusat di otak mengalami gangguan, sehingga koordinasi dari sistem saraf di otak tidak dapat mengirimkan sinyal ke sistem panca indera.
Terganggunya pengiriman sinyal ke sistem panca indera penderita epilepsi dapat disebabkan oleh beberapa hal seperti pernah mengalami trauma kepala berupa benturan atau cedera dibagian kepala, atau menderita tumor otak. Penyakit epilepsi dapat muncul karena penderita mengalami kerusakan otak pada saat dilahirkan. Namun selain penyebab yang telah disebutkan di atas, penyebab epilepsi masih belum dapat dipastikan.

Epilepsi yang berkembang di tengah masyarakat adalah semacam penyakit yang ditandai dengan kejang-kejang tiba-tiba serta mengeluarkan air liur berwarna putih. Pada umumnya epilepsi dapat muncul karena penderita mengalami kelelahan atau mengalami benturan dibagian kepala, yang disusul dengan tidak sadarkan diri, terjatuh, tubuh tegang, lalu disusul dengan gerakangerakan kejang tanpa terkendali di seluruh tubuh. Kejang biasanya berlangsung paling lama lima menit. Sesudahnya penderita bisa mengalami sakit kepala, linglung sementara dan merasa sangat lelah. Biasanya penderita tidak dapat mengingat apa yang terjadi setelah kejang. Tulisan ini akan mengkaji mengenai epilepsi dalam berbagai ragam budaya.

\section{Pembahasan}

\section{Epilepsi dari Beragam Budaya}

Menurut Desjarlais, Eisenberg, Good, \& Kleinman (1995) pada beberapa negara masih ditemukan adanya kesalahpahaman, diskriminasi, serta masih adanya stigma sosial yang negatif terhadap penderita epilepsi. Liveneh dan Antonak (dalam Bishop \& Hermann, 2000) mengemukakan bahwa stigma, sikap negatif, dan persepsi yang salah tentang penderita epilepsi ditemukan di setiap daerah atau negara. Kesalahpahaman, diskriminasi, dan stigma sosial yang negatif tersebut membuat 
mereka menjadi terjebak dalam kegelapan dan cenderung menutup diri (Desjarlais, et al. 1995). Masalah-masalah tersebut terjadi hampir pada setiap negara dan budaya. Berikut ini beberapa fakta yang ditemukan WHO. Di Kamerun, terdapat kepercayaan bahwa epilepsi disebabkan oleh pengaruh setan yang seketika merasuki tubuh si penderita. Di Cina, epilepsi mengurangi hak seseorang untuk menikah, terutama pada penderita wanita. Survei tahun 1992 menunjukkan bahwa $72 \%$ orang tua melarang anaknya menikah dengan penderita epilepsi. Di beberapa daerah di India, ada tindakan pengusiran setan pada diri penderita dengan cara mengikatnya pada pohon, memukul, mencukur sebagian rambutnya, memeras lemon dan jus lain pada kepala, lalu membuatnya kelaparan. Di Indonesia, epilepsi dianggap sebagai gangguan yang bersifat mistis. Di Liberia, Swazilan, dan negara Afrika lainnya, epilepsi dikaitkan dengan ilmu sihir. Di Nepal, epilepsi dianggap berkaitan dengan ilmu sihir dan refleksi red colour, dan penderita epilepsi kadang disirami air pada dahinya. Di Belanda pada tahun 1996, ODE dicambuk lalu diisolasi karena epilepsi dianggap berkaitan dengan ilmu sihir. Di Uganda dan negara-negara lainnya, epilepsi dianggap menular, sehingga penderita harus diasingkan.

Epilepsi bukanlah penyakit baru, penyakit ini sudah dialami sejak zaman kuno. Pada zaman dahulu epilepsi dikenal sebagai bentuk pengalaman religi yang dikaitkan dengan penyakit setan dan disebut sebagai penyakit suci karena serangan epilepsi terjadi disebabkan oleh serangan setan. Selain itu penyakit epilepsi dianggap sebagai serangan makluk halus atau kesurupan. Seorang penderita epilepsi dianggap bisa memiliki kemampuan untuk berkomunikasi dengan dunia lain sehingga dalam beberapa suku bangsa, penderita epilepsi malah diangkat menjadi dukun.

Di beberapa budaya, epilepsi malah tidak diartikan dengan pengalaman spiritual, melainkan identik dengan kegilaan. Para penderita ini dijauhi, dikucilkan, bahkan sampai dipenjarakan.

Epilepsi di sebuah negara Afrika bernama Tanzania, dihubungkan dengan roh-roh jahat, ilmu hitam, sihir, atau keracunan. Orang-orang ini menganggap epilepsi adalah penyakit menular. Di zaman Romawi kuno epilepsi dikenal dengan istilah morbus comitialis yang berarti penyakit aula perakitan, salah satu bentuk kutukan dari para dewa penguasa Romawi kuno. Penganut animisme Hmong menganggap epilepsi sebagai serangan dari roh jahat. Penderita epilepsi yang terkena serangan dari roh jahat ini diyakini bisa memiliki kekuatan magis.

Bangsa Yunani kuno mempunyai pandangan kontradiktif tentang penyakit ini. Mereka menganggap epilepsi sebagai suatu bentuk kerasukan spiritual, tetapi juga mengaitkan kondisi ini dengan kejeniusan dan keilahian. Salah satu julukan yang diberikan pada penyakit ini adalah penyakit keramat. Di Salpetriere, tempat lahirnya paham Neurologi Modern, seorang Neurologi modern Jean Martin Charcot mengungkapkan bahwa penderita epilepsi mengalami keterbelakangan mental, mengalami sifilis yang kronis dan melakukan tindak kriminal. Penderita epilepsi ditempatkan bersama penderita sakit jiwa, yang menderita sifilis kronis, dan gila secara kriminal. Di Italia bagian Utara, epilepsi secara tradisional pernah dikenal sebagai penyakit Santo Valentine.

\section{Epilepsi di Indonesia}

Di Indonesia, epilepsi dikenal sebagai "ayan" atau "sawan". Banyak masyarakat masih mempunyai pandangan yang keliru 
dan beranggapan bahwa epilepsi bukanlah penyakit tapi karena masuknya roh jahat, kesurupan, guna-guna atau suatu kutukan. Mereka juga takut memberi pertolongan karena beranggapan epilepsi dapat menular melalui air liur. Di daerah NTT epilepsi lebih dikenal dengan istilah "mati kambing". Hal itu dikarenakan masyarakat memiliki pandangan yang keliru dimana mereka menganggap bahwa epilepsi bukanlah penyakit tapi terjadi karena masuknya roh jahat, kesurupan, guna-guna atau suatu kutukan. Anggapan ini terjadi karena epilepsi terjadi ditempat umum, secara tiba-tiba, dan disaksikan oleh banyak orang sehingga menyebabkan berbagai persepsi yang keliru.

Pada dasarnya masyarakat NTT menyebutkan bahwa ayan atau epilepsi adalah penyakit akibat adanya guna-guna atau adanya kepercayaan terhadap hal-hal gaib, yang mengakibatkan setiap penyakit yang ada itu diakibatkan oleh adanya orang yang membuat karena faktor maslah keluarga atau faktor dendam. Penyebab penyakit ini sudah menjadi budaya yang tidak dapat hilang dari pemikiran masyarakat yaitu adanya kutukan. Pengertian masyarakat akan penyebab terjadinya penyakit ini sudah menjadi turun menurun kesetiap genarasi mereka. Sehingga penyebab penyakit epilepsi ini sudah menjadi masalah sosial budaya yang secara turun temurun dalam pemikiran masyarakat. Beberapa faktor yang mengakibatkan adanya kepercayaan terhadap hal-hal tersebut; (1) Masyarakat masih mempunyai pemikiran tradisional, (2) Kurangnya pemahaman akan beberapa penyakit akan beberapa jenis kesehatan, (3) Minimnya jasa pelayanan kesehatan di pedesaan sehingga para masyarakat pedesaan lebih banyak memilih menggunakan obat yang tradisional atau masih terkait dengan hal-hal gaib, dan (4) Banyaknya kesenjangan antara masyarakat sehingga banyak anggapan bahwa suatu penyakit itu merupakan perbuatan antara sesama masyarakat karena adanya unsur dendam.

\section{Epilepsi di Afrika dan Komunitas Afrika- Amerika}

Afrika Amerika adalah kelompok minoritas terbesar ketiga di Kanada. Pasien epilepsi di Afrika $80 \%$ menerima pengobatan yang tepat. Ada sekitar 3 hingga 4 juta orang epilepsi di Afrika, dan untuk bisa hidup mereka menggunakan obat-obatan konvensional. Terapi alternatif sering digunakan sebelum adanya fasilitas untuk konsultasi di perawatan kesehatan konvensional. Mayoritas pasien yang hidup dengan epilepsi didorong oleh keluarga dan teman-teman untuk menggunakan pengobatan alternatif.

Epilepsi di Nigeria, terapi herbal adalah bentuk paling populer dari obat tradisional. Obat herbal untuk epilepsi biasanya campuran dari tanaman yang memiliki antikejang, antipiretik, atau anti bakteri. Penyembuh spiritual juga umum di Nigeria karena epilepsi diduga terkait dengan kunjungan iblis, ilmu sihir atau roh. Untuk membersihkan pasien tersebut dari gangguan menggunakan tarian ritual dan mantra. Masalah yang umum di Nigeria adalah bahwa epilepsi dianggap menular. Pengobatannya dengan menyodorkan tungkai pasien ke dalam api, menggosok merica ke mata dan wajah mereka, dan minum air kencing sapi, pengobatan yang dapat menyebabkan radang paru-paru.

Epilepsi di Uganda, disebut ensimbu dan mengacu pada kejang grand mal. Penyakit ini dianggap menular dan dibawa oleh ilmu sihir. Hambatan sosial, di mana orang harus makan dan tidur saja, meninggalkan sekolah, tidak bermain dengan anak lainnya dan kemungkinan besar tidak akan menikah. Ensimbu dianggap akibat sihir, 
oleh karena itu diyakini bahwa pengobatan barat tidak efektif.

Epilepsi di Kamerun, dikenal sebagai nwaa atau melemparkan seseorang ke tanah, dianggap menular dan disebabkan oleh penyihir. Epilepsi juga mengacu pada banyaknya busa di perut yang meluap dan naik ke kepala, sehingga kejang. Orang dengan epilepsi dianggap kerasukan setan. Pengobatannya dengan diet khusus untuk mengontrol busa yang diproduksi di perut

Di Malawi, epilepsi disebabkan oleh serangga yang bergerak di dalam perut. Pengobatannya dengan campuran air dari akar, menyebabkan muntah yang diduga untuk membersihkan perut serangga. Di Swaziland, epilepsi dikenal sebagai sifosekuwa (penyakit jatuh) atau sitfuluwane Disebabkan oleh sihir, yang mengirimkan hewan jahat atau roh ke dalam tubuh dan menyebabkan kejang.

\section{Epilepsi di China}

Epilepsi adalah konsekuensi dari tindakan berbagai setan atau roh, kemudian diyakini mulai dengan kepemilikan oleh setan dan berakhir ketika setan meninggalkan tubuh. Dalam pengobatan tradisional Cina, epilepsi dan serangan epilepsi tidak dianggap dibawa oleh agen supernatural. Terjemahan Cina dari epilepsi adalah Dian, yang berarti jatuh sakit, dan serangan epilepsi adalah Xian, yang berarti kejang. Terapi dan pengobatannya dengan mengonsumsi ramuan-ramuan herbal akupuntur, dan pijat untuk mencapai keseimbangan fungsi dari Yin (negatif) dan Yang (positif), serta kelima elemen tubuh, yaitu limpa, hati, jantung, paru-paru, dan ginjal, yang berinteraksi dengan unsur-unsur secara kompleks untuk menghasilkan keseimbangan tertentu dalam tubuh (Sahni, 2008).

\section{Epilepsi di Brazil}

Telah banyak penelitian epilepsi yang dilakukan di Brasil. Penelitian ini tidak hanya berfokus pada kejadian dan penyebab epilepsi, tetapi juga mengeksplorasi sikap, pendapat, dan kepercayaan tradisional yang dipegang oleh rakyat yang berhubungan dengan epilepsi. Pasien dirawat di rumah sakit, namun, biasanya mereka yang mengalami status epileptikus, sering kejang, atau komplikasi dengan kondisi mereka.

Sayangnya, meskipun Negara kuat dalam ekonomi, tetapi menjadi salah satu negara terburuk dalam hal pendidikan dasar. Ditemukan bahwa $80 \%$ dari siswa di Brasil bahkan tidak tamat SD. Tingkat rendah seperti pendidikan di seluruh negeri berkontribusi terhadap stigma yang terkait dengan epilepsi dan mencegah penerimaan sosial yang mungkin dari mereka yang hidup dengan gangguan tersebut. Seiring dengan stigma, ada banyak faktor lain yang berkontribusi terhadap kualitas hidup yang buruk yang dialami oleh orang yang hidup dengan epilepsi. Menurut Asosiasi Brasil Epilepsi (ABE), overprotection, rendah diri, terisolasi, depresi dan kecemasan merupakan beban tambahan dan menciptakan hambatan untuk kehidupan yang aktif.

\section{Epilepsi di Ekuador}

Angka prevalensi epilepsi di Ekuador adalah $2-3 \%$ yang $50 \%$ disebabkan oleh infeksi oleh Taenia solium (cacing pita pada babi). Perempuan lebih banyak mencari bantuan medis daripada laki-laki. Penyakit ini disebabkan karena memiliki terlalu banyak masalah di pikiran dan juga kemarahan. Penderita epilepsi dianggap sakit, lemah, atau gila dan juga masyarakat percaya bahwa mereka yang hidup dengan epilepsi akan mengalami masalah yang berhubungan dengan masyarakat umum. 


\section{Epilepsi di Spanyol}

Epilepsi dianggap sebagai sebuah penyakit psikologis. Bukan penyakit neurologis. Penderita dianggap sebagai orang yang berbahaya karena watak kerasnya.

\section{Epilepsi di India}

Dari satu miliar orang yang tinggal di India, sekitar sepuluh juta memiliki epilepsi. Tujuh belas November telah dinyatakan sebagai Hari Epilepsi Nasional oleh Asosiasi India. Epilepsi di India sering dianggap dengan kegilaan. Orang-orang dengan epilepsi tidak hanya didiskriminasi oleh masyarakat saja, tetapi juga pemerintahan India. Baru-baru ini pemerintah India membuat perubahan pada undang-undang mereka mengenai orang-orang dengan epilepsi. Sebelumnya, epilepsi secara hukum dianggap sebagai alasan untuk perceraian oleh UU Perkawinan Hindu tahun 1955 dan Undang-Undang Perkawinan Khusus 1954, jika salah satu pria atau wanita mengalami kejang berulang sebelum menikah. Perceraian diizinkan oleh Asosiasi India 1976 karena epilepsi didefinisikan sebagai kegilaan, atau menyebabkan kegilaan. Yang cukup menarik, sebagian besar stigma sosial yang terkait dengan gangguan ini terletak pada orang kaya di perkotaan, dan bukan kaum miskin di pedesaan. Orang miskin pedesaan tidak menganggap epilepsi masalah besar karena keluarga merawat mereka yang sakit, pasien dengan epilepsi tidak ditinggalkan oleh keluarga, dan mereka diizinkan untuk menikah dan diterima dalam masyarakat.

Karena stigma yang lebih besar dikaitkan dengan kelas elit perkotaan India, banyak orang yang ragu-ragu menginformasikan orang lain tentang gangguan mereka. Keluarga mereka juga menghindari berbagi informasi karena mereka takut akan penolakan sosial. Karena perjodohan agak populer di India, banyak yang takut jika orang lain tahu tentang epilepsi pada mereka atau anak putri. Orang-orang raguragu untuk menikah dengan seseorang dengan masalah epilepsi karena mereka takut anak mereka juga dapat tumbuh dengan kondisi epilepsi. Meskipun banyak dari kaum elit perkotaan berpendidikan, mereka memiliki suatu pegangan yang kuat pada kesalahpahaman dan takhayul yang mencegah epilepsi dari menjadi gangguan yang dapat diterima secara sosial.

Di masa lalu, dan mungkin bahkan sekarang, pasien dengan gangguan kejang percaya bahwa mereka adalah bentuk hukuman atas dosa-dosa yang dilakukan di kehidupan lampau. Stigma ini memungkinkan orang-orang untuk menerima kondisi mereka. Sikap seperti bertahan karena kekurangan dalam pendidikan tidak hanya orang-orang yang tinggal di desa-desa, tetapi juga pada penyedia layanan kesehatan lokal.

Penyebab paling umum dari epilepsi adalah cedera kepala, infeksi otak, ensefalitis, meningitis dan demensia. Epilepsi sebagai akibat dari infeksi malaria dan TBC merupakan penyebab yang agak umum. Secara khusus, di India, konsumsi makanan penuh dengan telur cacing pita merupakan penyebab utama epilepsi. Larva dari telur ini memasuki aliran darah setelah menetas.

Sistem kedokteran di India dikenal sebagai Ayurveda, yang berarti ilmu kehidupan. Ayurveda bekerja untuk memperbaiki ketidakseimbangan dalam tubuh yang dapat menyebabkan penyakit atau kesehatan yang buruk. Ayurveda adalah sistem medis lengkap tertua di dunia, setelah berasal ribuan tahun yang lalu. Hal ini masih digunakan sampai sekarang dan telah mempengaruhi beberapa budaya lain. Saat ini, Ayurveda sedang diintegrasikan dengan pengobatan Barat untuk pengobatan banyak penyakit dan gangguan, seperti epilepsi. Prinsip-prinsip pengobatan 
ayurveda menyatakan bahwa ada lima elemen utama untuk setiap individu. Unsur-unsur ini meliputi eter, udara, api, air, dan bumi. Kombinasi dari unsur-unsur ini bertanggung jawab untuk mengarahkan kekuatan yang berbeda dalam tubuh yang terkait dengan gerakan, metabolisme atau pertumbuhan. Pengobatan Ayurveda berusaha untuk mengobati epilepsi dengan memblokir saluran hati dan pikiran yang mungkin tersumbat oleh kelebihan doshas atau humor. Pembukaan saluran ini dipraktekkan menggunakan berbagai suntikan dan obat pencahar.

\section{Epilepsi di Asia Selatan}

Istilah yang paling umum digunakan untuk epilepsi terlepas dari kelompok etnis adalah kata mirgee yang berarti 'cocok' tetapi memiliki konotasi yang sangat negatif. Penjelasan umum tentang epilepsi pada semua kelompok berkaitan dengan stres, riwayat keluarga, trauma fisik, dan masalah kesehatan sebelumnya. Beberapa Muslim percaya epilepsi disebabkan oleh kepemilikan roh dan banyak dikaitkan ke 'kehendak Allah', sedangkan beberapa orang Hindu dan Sikh percaya dosa yang dilakukan di kehidupan sebelumnya menyebabkan kondisi tersebut. Anggota masyarakat menambahkan penjelasan lain seperti pernikahan kerabat. Beberapa individu merasa bahwa orang-orang dari masyarakat luas dijauhi karena takut terkena epilepsi. Masyarakat luas melihat orang-orang dengan epilepsi seperti memiliki beberapa jenis cacat.

\section{Epidemiologi}

Epilepsi merupakan salah satu gangguan saraf serius yang paling umum terjadi yang mempengaruhi sekitar 65 juta orang di seluruh dunia. Ia mempengaruhi $1 \%$ penduduk pada usia 20 tahun dan 3\% penduduk pada usia 75 tahun. Lebih banyak terjadi pada laki-laki daripada perempuan, tetapi secara menyeluruh selisihnya cukup kecil. Sebagian besar penderita $(80 \%)$ tinggal di negara berkembang.

Angka penderita epilepsi aktif saat ini berkisar pada 5-10 per 1.000; epilepsi aktif diartikan sebagai penderita epilepsi yang pernah mengalami kejang paling tidak satu kali dalam lima tahun terakhir. Epilepsi berawal setiap tahun dalam 40-70 per 100.000 di negara maju dan $80-140$ per 100.000 di negara berkembang. Kemiskinan merupakan sebuah risiko dan mencakup baik bertempat asal dari sebuah negara yang miskin maupun berstatus sebagai orang miskin relatif terhadap orang lain di dalam negara yang sama. Di negara maju, epilepsi paling umum bermula pada orang muda atau orang lansia. Di negara berkembang, awal epilepsi lebih umum terjadi pada anak-anak yang berusia lebih tua dan pada orang dewasa muda karena lebih tingginya angka trauma dan penyakit menular. Di negara maju, jumlah kasus per tahun telah mengalami penurunan pada anak-anak dan peningkatan pada orang lansia antara tahun 1970-an dan 2003. Hal ini sebagian disumbang oleh kesintasan pasca-stroke yang lebih baik pada orang lansia.

Menurut Kleinman (1995) di Amerika Utara menunjukkan bahwa di antara pasien epilepsi dalam pengobatan biomedis yang diikuti selama dua puluh tahun, dua pertiga akan menjadi bebas kejang selama lima tahun atau lebih. Mereka juga melaporkan bahwa kejang berulang di $25 \%$ pasien yang melanjutkan pengobatan, sedangkan terjadi pada $45 \%$ dari mereka yang berhenti minum obat. Penelitian epidemiologi klinis menunjukkan bahwa jika kejang tidak terkontrol pada tahun pertama setelah onset, hanya $60 \%$ pasien yang dapat diharapkan untuk memasuki remisi dan setelah empat tahun kejang tidak terkendali, angka ini turun drastis sampai $10 \%$. Ahli 
epilepsi China belum menerbitkan data pada masing-masing isu prognostik. Temuan menunjukkan bahwa Cina melakukan penilaian retrospektif $40 \%$ dari 448 pasien dengan epilepsi yang tidak menerima obat anti-epilepsi telah pergi ke remisi selama dua tahun dan $27 \%$ telah melakukannya selama lima tahun (Zhou 1989).

\section{Psikososial}

Epilepsi bisa memiliki efek merugikan pada kesejahteraan sosial dan psikologis seseorang. Efek-efek ini bisa termasuk isolasi sosial, stigmatisasi, atau ketidakmampuan.-Efek-efek itu bisa menyebabkan pencapaian prestasi belajar yang rendah dan kesempatan kerja yang buruk. Kesulitan belajar umum ditemukan pada penderita epilepsi, dan dalam Stigma epilepsi bisa juga mempengaruhi keluarga penderita. Gangguan-gangguan tertentu muncul lebih sering di kalangan penderita epilepsi, sebagian tergantung pada gejala epilepsi yang ada, termasuk depresi, gangguan cemas, dan migrain.

Rasa malu tersebar luas di antara penderita epilepsi serta emosi negatif lainnya. Beberapa aspek dari stigma yang berhubungan dengan epilepsi adalah takut kejang, cedera, kematian, malu, kehilangan pekerjaan, kesempatan pendidikan, atau tidak diizinkan menikah. Banyak ahli kesehatan sering tidak mengetahui tentang epilepsi dari penyebabnya, diagnosis, pengobatan, aspek psikososial dan penyakit mental dalam hal stigma tersebut.

Stigma umum dialami oleh penderita epilepsi di seluruh dunia. Hal ini dapat mempengaruhi orang secara ekonomi, sosial, dan budaya. Di Cina, epilepsi telah dilaporkan mengancam aspirasi seluruh keluarga serta peluang dari individu dengan epilepsi. Beberapa orang tua bahkan keberatan anak-anak mereka bermain dengan penderita epilepsi. Dari itu kemudian banyak orang yang mencoba untuk menyembunyikan epilepsi mereka. Di India dan Cina, epilepsi dapat digunakan sebagai penentu untuk menolak pernikahan. Orangorang di daerah tertentu masih percaya bahwa penderita epilepsi itu terkutuk. Di Tanzania, seperti di bagian lain Afrika, epilepsi dihubungkan dengan kerasukan roh jahat, tenung, atau keracunan serta oleh banyak orang dipercayai dapat menular yang tidak ada buktinya. Sebelum tahun 1970 di Britania Raya ada hukum yang melarang penderita epilepsi untuk menikah. Semua stigma yang ada dapat membuat penderita epilepsi menyangkal jika mereka pernah mengalami kejang.

\section{Pengobatan Konvensional}

Sebagian besar orang dengan epilepsi di sub-Sahara Afrika perlu dirawat oleh penyedia layanan kesehatan primer di tingkat masyarakat. Oleh karena itu, ahli saraf sangat perlu untuk dilibatkan dalam program pendidikan yang terorganisir untuk melatih perawat, petugas klinis, dan petugas kesehatan masyarakat, sehingga mereka dapat melaksanakan layanan dasar yang dibutuhkan untuk menangani masalah epilepsi.

\section{Ayurveda}

Ayurveda bekerja untuk memperbaiki ketidakseimbangan dalam tubuh yang dapat menyebabkan penyakit atau kesehatan yang buruk. Saat ini, Ayurveda sedang diintegrasikan dengan pengobatan Barat untuk pengobatan banyak penyakit dan gangguan, seperti epilepsi. Prinsipprinsip pengobatan Ayurveda menyata-kan bahwa ada lima elemen utama untuk setiap individu. Unsur-unsur ini meliputi space, udara, api, air, dan bumi. Kombinasi dari unsur-unsur ini bertanggung jawab untuk mengarahkan kekuatan yang berbeda 
dalam tubuh yang terkait dengan gerakan, metabolisme atau pertumbuhan. Pengobatan Ayurveda berusaha untuk mengobati epilepsi dengan membuka saluran hati dan pikiran yang mungkin tersumbat oleh kelebihan doshas atau humor. Pembukaan saluran ini dipraktekkan menggunakan berbagai suntikan dan obat pencahar. Tujuan terapi ini adalah pengobatan internal (Charaka Samhita) dan operasi (Sushruta Samhita). Terapi Ayurveda berkaitan dengan menyelaraskan atau mensinergikan kinerja organ tubuh, pijat, meditasi, dan lain-lain.

\section{Akupuntur dan Herbal}

Akupunktur telah dikenal untuk mengurangi kejang dan juga mengontrol aktivitas otak yang abnormal yang menyebabkan kejang. Studi di Cina telah menetapkan bahwa pengobatan epilepsi di mana akupunktur dan pijat digunakan bersama dengan tanaman herbal tertentu memiliki hasil terbaik. Sebuah studi di Jerman yang melibatkan hampir seratus orang menetapkan bahwa pengobatan akupunktur selama periode sampai dengan 18 bulan menunjukkan peningkatan yang nyata dalam $65 \%$ dari kasus.

Ada dua jenis terapi pijat yang telah diketahui efektif dalam mengobati pasien epilepsi. Mereka adalah terapi Cranial-sacral dan aromaterapi. Terapi Cranial-sacral membantu untuk mendapatkan cairan bergerak bebas di sekitar otak sehingga melepaskan penyumbatan yang dapat menyebabkan kejang. Aromaterapi menggunakan Jasmine membuat pasien mengasosiasikan aroma dengan relaksasi dan ini negara yang disebabkan relaksasi dapat mengurangi kemungkinan kejang.

\section{Penutup}

Epilepsi terjadi di hampir seluruh negara di dunia. Epilepsi bisa diderita oleh siapapun, seperti yang telah disebutkan epilepsi merupakan gangguan susunan saraf pusat yang dicirikan oleh terjadinya kejang yang bersifat spontan dan berkala. Kejang dapat diartikan sebagai modifikasi fungsi otak yang bersifat mendadak dan sepintas, yang berasal dari sekolompok besar sel-sel otak, bersifat singkron dan berirama. Bangkitnya epilepsi terjadi apabila proses eksitasi didalam otak lebih dominan dari pada proses inhibisi.

Epilepsi dianggap berbeda pada setiap negara. Epilepsi diartikan sebagai bentuk pengalaman religi yang dikaitkan dengan penyakit setan dan disebut sebagai penyakit suci, dianggap sebagai serangan makluk halus atau kesurupan, dihubungkan dengan roh-roh jahat, ilmu hitam, sihir, atau keracunan, dihubungkan dengan pengalaman spiritual dan juga ada yang menganggap sebagai kegilaan.

Epilepsi memiliki efek merugikan pada kesejahteraan sosial dan psikologis seseorang. Efek-efek ini termasuk isolasi sosial, stigmatisasi, atau ketidakmampuan yang bisa menyebabkan pencapaian prestasi belajar yang rendah dan kesempatan kerja yang buruk. Stigma sangat memengaruhi penderita epilepsi. Beberapa aspek dari stigma yang berhubungan dengan epilepsi adalah takut kejang, cidera, kematian, malu, kehilangan pekerjaan, kesempatan pendidikan, atau tidak diizinkan menikah. Banyak ahli kesehatan sering tidak mengetahui tentang epilepsi dari penyebabnya, diagnosis, pengobatan, aspek psikososial dan penyakit mental dalam hal stigma tersebut.

Banyak pengobatan yang bisa digunakan untuk mengobati penyakit epilepsi pada penderita, yaitu: dengan konvensio- 
nal, terapi herbal, terapi akupuntur, terapi tradisional atau non konvensional dan Ayurveda. Beberapa kendala yang sering dijumpai penderita epilepsi di beberapa negara terutama negara berkembang adalah pengetahuan dan akses pengobatan yang terbatas, stigma dan diskriminasi, tidak dapat mengakses pelayanan kesehatan, kurangnya pengetahuan tentang penyebab dan pengobatan epilepsi dan kondisi ekonomi yang rendah.

\section{Daftar Pustaka}

Baker, G. A., \& Jacoby, A. (2000). The problem of epilepsi, Quality of life in epilepsi: Beyond seizure counts in assessment and perlakuan. Amsterdam: Harwood Academic Publishers.

Bishop, M., \& Hermann, B. (2000). Impact of epilepsi on quality of life: A review. In Baker, G. A., \& Jacoby, A. Quality of life in epilepsi: Beyond seizure counts in assessment and perlakuan (pp 104-117). Amsterdam: Harwood Academic Publishers.

Desjarlais, R., Eisenberg, L. Good., B., \& Kleinman, A. (1995). World mental health: Problems and priorities in low-income countries. New York: Oxford university Press, Inc.

Fokusjabar.com/2012/12/04/aeh-disangkatewas-ternyata-epilepsi/

Kleinman, A. B. (1995). 7 The social course of epilepsi chronic illness as social experience in interior China. University of California Press.

Sahni, P. (2008). Epilepsi in the Chinese community. Epilepsi Ontario. Diunduh dari: http://www. epilepsiontario.org. 8 Maret 2008.

Sahni, P. (2008). Epilepsi in the Africa and the African American community. Epilepsi Ontario. Diunduh dari: http://www.epilepsiontario.org tanggal 8 Maret 2008.

Sahni, P. (2008). Epilepsi in the Latin community. Epilepsi Ontario. Diunduh dari: http://www. epilepsiontario.org. tanggal 7 Maret 2008.

Sahni, P. (2008). Epilepsi in the South Asian community. Epilepsi Ontario. Diunduh dari: http://www.epilepsiontario.org. tanggal 7 Maret 2008.

Sahni, P. (2008). Epilepsi in Africa and the African American community. Epilepsi Ontario. Diunduh dari: http://www.epilepsiontario.org tanggal 8 Maret 2008.

WHO. (2009). Epilepsi. Artikel. Diunduh dari:

http://www.who.int/mediacentre/factsh eets/fs999/en/ tanggal 28 April 2009.

Zhou, S. (1989). Spontaneous remission of epilepsy. Chinese Journal of Neuro surgery. http://en.cnki.com.cn /Article _en/CJFDTOTAL- ZHSW1989S1008.htm 